\title{
Functional capacity and dependency in transfer and dressing are associated with depressive symptoms in older people
}

This article was published in the following Dove Press journal:

Clinical Interventions in Aging

4 February 2014

Number of times this article has been viewed

\author{
Gustaf Boström' \\ Mia Conradsson' \\ Erik Rosendahl',2 \\ Peter Nordström' \\ Yngve Gustafson' \\ Håkan Littbrand ${ }^{1,2}$ \\ 'Department of Community \\ Medicine and Rehabilitation, \\ Geriatric Medicine, Umeå University, \\ Umeå, Sweden; ${ }^{2}$ Department \\ of Community Medicine and \\ Rehabilitation, Physiotherapy, \\ Umeå University, Umeå, Sweden
}

Background: This study examined associations between depressive symptoms and functional capacity, overall dependency in personal activities of daily living (ADLs), and dependency in individual ADL tasks, respectively, in people with a high mean age, large range of functional capacity, and wide spectrum of dependency in ADLs.

Methods: Cross-sectional data from three studies were used. A total of 392 individuals living in community and residential care facilities were included. Mean age was 86.2 years, $72 \%$ were women, $75 \%$ were dependent in ADLs, $42 \%$ had depression, and $39 \%$ had dementia. Depressive symptoms were assessed with the 15-item Geriatric Depression Scale (GDS-15), functional capacity with the Berg Balance Scale (BBS), and ADLs with the Barthel ADL Index. Multiple linear regression analyses with comprehensive adjustments were performed between GDS-15 and BBS, GDS-15 and Barthel ADL Index, and GDS-15 and each individual ADL task, separately.

Results: GDS-15 score was associated with BBS score (unstandardized $b=-0.03, P=0.008$ ), but not with Barthel ADL Index score (unstandardized $b=-0.07, P=0.068$ ). No significant interaction effects of sex, dementia, or living conditions were found in these associations. Among individual ADL tasks, dependency in transfer (unstandardized $b=-1.03, P=0.007$ ) and dressing (unstandardized $b=-0.70, P=0.035$ ) were associated with depressive symptoms.

Conclusion: Functional capacity seems to be independently associated with depressive symptoms in older people living in community and residential care facilities, whereas overall ADL performance may not be associated. Dependency in the individual ADL tasks of transfer and dressing appear to be independently associated with depressive symptoms and may be an important focus of future interdisciplinary multifactorial intervention studies.

Keywords: aged 80 and over, residential facilities, independent living, depression, activities of daily living

\section{Introduction}

Depression is currently the leading cause of burden of disease in high- and middleincome countries, and it is predicted to be the leading cause worldwide in $2030{ }^{1}$ Among older people, the incidence and prevalence of depression seem to increase with age. ${ }^{2,3}$ Depression is also more prevalent among older people living in residential care facilities, ${ }^{2}$ those with cognitive impairment, ${ }^{4,5}$ and women. ${ }^{6}$ Drug treatment for depression seems to have a limited effect in older people ${ }^{7}$ and may have no effect in people with dementia. ${ }^{8}$ To find alternative ways of treating or preventing depression in older age, increasing our knowledge about factors associated with this condition is important.
Correspondence: Gustaf Boström Department of Community Medicine and Rehabilitation, Geriatric Medicine, Umeå University, SE-90I87 Umeå, Sweden

Tel +46907858755

Fax +4690130623

Email gustaf.bostrom@germed.umu.se 
Despite depression's increased prevalence with age, chronological age does not seem to be an independent risk factor for this condition in adjusted models. ${ }^{9}$ Instead, the prevalence of many diseases and conditions associated with depression, such as stroke, dementia, malignancy, heart failure, dependency in activities of daily living (ADLs), and functional impairment, increases with age.$^{10}$ Risk factors for depression may impact individuals with advanced biological age differently than younger and healthier populations. Thus, results of research conducted in younger people may not be applicable to a very old population.

Even if the frequencies of depression, reduced functional capacity, and dependency in ADLs are high among very old individuals, few studies have investigated associations among these factors in a population including a majority of very old people. ${ }^{11-15}$ Three studies have included people with severe cognitive and physical impairments, ${ }^{11,12,15}$ but none of these studies have performed comprehensive adjustments for confounding factors, leaving the question of whether reduced functional capacity and dependency in ADLs are independent risk factors for depression in this population unanswered. Functional capacity and dependency in ADLs have been shown to be associated with depression among community-dwelling older people. ${ }^{16-18}$ Further examination of these associations is important because intervention programs may improve or prevent both of these factors, thereby reducing the prevalence of depression. Mediators of the association between depression and improvement in functional capacity or reduced dependency in ADLs may include better self-efficacy, sense of control, self-esteem, the ability to participate in social activities, and an enhanced level of daily physical activity. ${ }^{17,19-22}$

Although functional capacity is correlated strongly with overall dependency in ADLs, these measures provide different information, and their associations with depression might differ. An individual's functional capacity reflects the ability to execute a task in a test situation related to a daily physical activity, such as getting out of a chair, climbing stairs, or walking. In contrast, the degree of dependency in ADLs is a measure of disability based on the assistance a person receives with these activities ${ }^{23}$ and may be more influenced by factors such as cognition, environmental demands, use of assistive devices, and the caregiver's estimation of the need for assistance. Furthermore, to better understand the association between dependency in ADLs and depression, the impact of individual components of this dependency on depressive symptoms must be explored. To our knowledge, no such study has been conducted to date. The aim of the present study was to examine associations between depressive symptoms and functional capacity, overall dependency in ADLs, and dependency in individual ADL tasks, respectively, in people with a high mean age, a large range of functional capacity, and a wide spectrum of dependency in ADLs. A secondary aim was to investigate whether sex, dementia, or living in a residential care facility influenced these associations.

\section{Methods}

\section{Study design and participants}

To gather data from participants of advanced age with wide ranges of functional capacity and dependency in ADLs and many coexisting diseases, the present study used a merged dataset derived from one population-based study of a very old population, the Umeå $85+/$ Gerontological Regional Database (GERDA) Study (2000-2001), ${ }^{24}$ and baseline data from two studies performed in residential care facilities in the urban municipality of Umeå: the Frail Older PeopleActivity and Nutrition (FOPANU; 2002) (25 $^{25}$ and Residential Care Facilities-Mobility, Activity and Nutrition (REMANU; $2004)^{26}$ studies. For people participating in more than one of the three studies, data from only the first study were included.

The sole inclusion criterion for the population based Umeå $85+/$ GERDA Study was being of a certain age; $50 \%$ of people aged 85 years and all people aged 90 and $\geq 95$ years were asked to participate. Of 319 people, 253 (79\%) agreed to participate (Figure 1). The FOPANU Study was a randomized, controlled, exercise intervention trial, and the REMANU study was observational. The inclusion criteria for these two studies were living in a residential care facility, age $\geq 65$ years, dependency in personal ADLs, ability to rise from a chair with armrests with help from no more than one person, mini-mental state examination (MMSE) ${ }^{27}$ score $\geq 10$, and approval from the resident's physician. The facilities comprised private apartments with access to common dining rooms, alarms, and onsite nursing and care. Some facilities also had specialized units for people with dementia, with private rooms and staff on hand. In the FOPANU and REMANU studies, 191/262 (73\%) and 63/104 (61\%) eligible people agreed to participate (Figure 1). Informed consent was obtained from all participants. When appropriate, ie, in cases of cognitive impairment, a next of kin was contacted for informed consent. The studies were approved by the Regional Ethical Review Board in Umeå (\$99-326, $\S 391 / 01$, and $\S 439 / 03)$. 


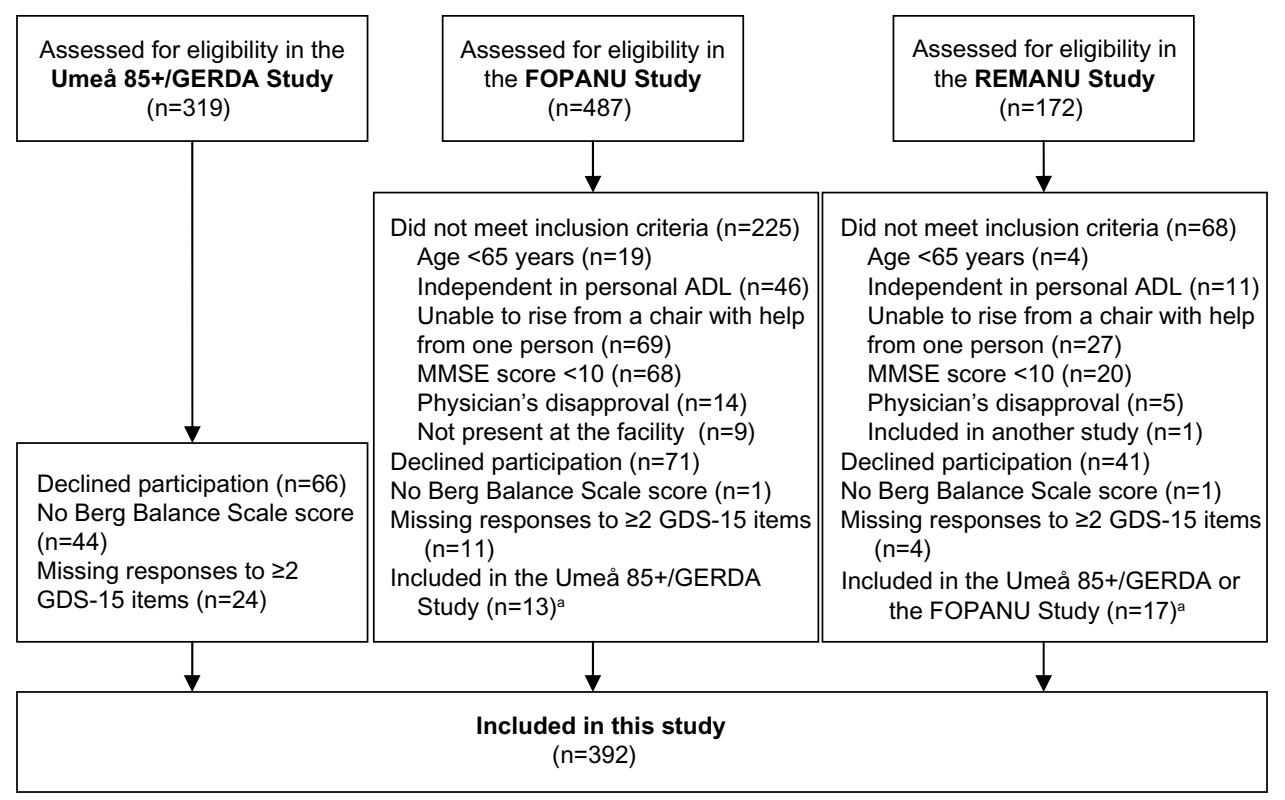

Figure I Flow chart of the inclusion process for this study.

Note: alf a person participated in more than one study, results from the first study were used.

Abbreviations: ADL, activities of daily living; FOPANU, Frail Older People-Activity and Nutrition; GDS-15, I5-item Geriatric Depression Scale; GERDA, Gerontological Regional Database; MMSE, mini mental state examination; REMANU, Residential Care Facilities-Mobility, Activity and Nutrition.

\section{Data collection and assessments}

In all three studies, trained investigators assessed and interviewed participants in their homes or in the living areas of the residential care facilities. In the Umeå 85+/GERDA Study, information about diagnoses and prescribed drugs was collected from participants and their medical records. When appropriate, relatives and/ or caregivers were contacted to confirm certain diagnoses. In the FOPANU and REMANU studies, residential care facility nurses obtained information from medical records. An experienced specialist in geriatric medicine carefully evaluated the gathered information of diagnoses, prescribed drugs, and results from assessments for verification of diagnoses in all three studies.

Depressive symptoms were assessed using the 15 -item version of the Geriatric Depression Scale (GDS-15). ${ }^{28}$ Items are structured by yes/no responses and scores range from 0 to 15 , with higher scores indicating the presence of more depressive symptoms. The GDS-15 has shown high sensitivity and specificity in the detection of clinical depression among people aged $\geq 85$ years ${ }^{29}$ and those living in residential care facilities. ${ }^{30}$ It has also been validated and judged to be useful among people with severe cognitive impairment. ${ }^{30,31}$ The GDS-15 was administered in interviews to facilitate completion by people with cognitive decline or functional impairment. One missing answer (scored 0 ) was allowed, but more than one missing answer resulted in the exclusion of a participant's data from the present study.

Functional capacity was assessed using the Berg Balance Scale (BBS), ${ }^{32}$ a well-established, valid, and reliable scale for older people, including those with cognitive impairment. ${ }^{26,33}$ The BBS measures functional balance capacity in 14 common everyday tasks of varying difficulty, including for example, standing from a seated position, transferring from one chair to another, standing and reaching forward, standing and turning $360^{\circ}$, and placing one foot at a time onto a step while standing. Thus, the scale reflects aspects of physical function other than balance, such as lower-limb strength and gait. Item scores range from 0 to 4 , and total scores range from 0 to 56 , with higher scores indicating better balance/functional capacity. ${ }^{33}$ People who exceed specified time limits or require supervision or physical or verbal guidance are given lower scores. The unavailability of a BBS score resulted in the exclusion of a participant's data from the present study.

ADLs were assessed using the ten-item version of the Barthel ADL Index, a well-established and valid measure of dependency in personal care and mobility ${ }^{34}$ that has demonstrated reliability among older people with impaired function. ${ }^{35}$ The Barthel ADL Index measures what a person does, rather than what he or she is able to do. Scores range from 0 to 20, with higher scores indicating a greater level of independence. In the FOPANU and REMANU studies, licensed practical nurses or nurse's aides who knew participants well were interviewed about participants' dependency in ADLs. In the Umeå 85+/GERDA Study, participants were interviewed and in cases of cognitive impairment, relatives and caregivers were contacted to confirm the scores. 
Visual impairment was considered to be present when a participant was unable to read a sentence printed in $5 \mathrm{~mm}$ capital letters. Hearing impairment was defined as the inability to hear a normal conversational tone at a distance of $1 \mathrm{~m}$. Measured height and weight were used to calculate each participant's body mass index $\left(\mathrm{kg} / \mathrm{m}^{2}\right)$. Cognitive function was assessed using the $\mathrm{MMSE}^{27}$ (score 0-30), with scores of 18-23 indicating moderate cognitive impairment and scores $<18$ indicating severe cognitive impairment. ${ }^{36}$

In all three studies, a specialist in geriatric medicine made all diagnoses of dementia and depression according to the criteria of the Diagnostic and Statistical Manual of Mental Disorders, Fourth Edition, Text Revision, ${ }^{37}$ based on assessments and documentation in medical records. However, depression diagnoses recorded in the medical records of patients receiving ongoing antidepressant treatment were also considered to indicate ongoing depression, regardless of the patients' responses to treatment. Response to treatment was defined as a GDS- 15 score $<5$ in individuals with a depression diagnosis and ongoing antidepressant treatment.

\section{Statistical analyses}

Descriptive characteristics (Table 1) were chosen in advance of analysis given the documented associations of these characteristics with depression. These associations were tested in univariate linear regression analyses, with GDS-15 score serving as the dependent variable. To further investigate each task in the Barthel ADL Index, they were each dichotomized as independent (maximum task score) or dependent (at least one point deducted). Differences in GDS-15 scores between these groups were evaluated using the independent samples $t$-test.

Univariate and multivariate linear regression analyses were used to investigate associations between GDS-15 and BBS, GDS-15 and Barthel ADL Index, and GDS-15 and each individual ADL task of Barthel ADL Index, separately. The depen-

Table I Participant characteristics and their association with I5-item Geriatric Depression Scale

\begin{tabular}{|c|c|c|c|}
\hline Characteristic & Total $(n=392)$ & Unstandardized $b(95 \% \mathrm{Cl})$ & $P$ \\
\hline Age (years) & $86.2 \pm 6.0(65-103)$ & $0.03(-0.02,0.08)$ & 0.20 \\
\hline Female sex & $282(72)$ & $0.27(-0.35,0.88)$ & 0.39 \\
\hline Living in residential care facility & $264(67)$ & $0.67(0.09,1.26)$ & 0.024 \\
\hline \multicolumn{4}{|l|}{ Diagnoses and medical conditions } \\
\hline Depression & $166(42)$ & $2.27(1.76,2.78)$ & $<0.001$ \\
\hline Dementia & $153(39)$ & $-0.49(-1.06,0.07)$ & 0.088 \\
\hline Previous stroke & $94(24)$ & $0.66(0.01,1.30)$ & 0.045 \\
\hline Urinary tract infection, current & $44(11)$ & $0.75(-0.12,1.62)$ & 0.091 \\
\hline Diabetes mellitus & $59(15)$ & $0.54(-0.23,1.31)$ & 0.17 \\
\hline Heart failure & $96(25)$ & $0.21(-0.43,0.85)$ & 0.52 \\
\hline Angina pectoris & $127(32)$ & $0.44(-0.15,1.03)$ & 0.14 \\
\hline Malignancy, in the last 5 years & $47(12)$ & $-0.76(-1.6 \mathrm{I}, 0.09)$ & 0.078 \\
\hline Constipation & $173(44)$ & $1.37(0.83,1.91)$ & $<0.001$ \\
\hline Osteoporosis & $125(32)$ & $0.37(-0.23,0.95)$ & 0.23 \\
\hline Rheumatic disease & $45(12)$ & $1.67(0.82,2.52)$ & $<0.001$ \\
\hline \multicolumn{4}{|l|}{ Regular use of drugs } \\
\hline Diuretics & $200(5 \mathrm{I})$ & $0.52(-0.03,1.07)$ & 0.065 \\
\hline Analgesics (not ASA) & $213(54)$ & $0.61(0.06,1.16)$ & 0.03 \\
\hline Benzodiazepines & $132(34)$ & $0.96(0.38,1.54)$ & 0.001 \\
\hline Antidepressants & $132(34)$ & $1.05(0.48,1.63)$ & $<0.001$ \\
\hline Neuroleptics & $72(18)$ & $0.20(-0.5 \mathrm{I}, 0.92)$ & 0.58 \\
\hline Acetylcholinesterase inhibitors & $37(9)$ & $-1.08(-2.01,-0.14)$ & 0.025 \\
\hline Number of drugs used regularly & $7.9 \pm 4.4(0-24)$ & $0.17(0.11,0.23)$ & $<0.001$ \\
\hline \multicolumn{4}{|l|}{ Assessments } \\
\hline Visual impairment & $82(21)(n=391)$ & $0.71(0.04,1.39)(n=391)$ & 0.039 \\
\hline Hearing impairment & $65(17)$ & $0.45(-0.29,1.19)$ & 0.23 \\
\hline Mini mental state examination $(0-30)$ & $20.5 \pm 6.0(8-30)(n=391)$ & $-0.06(-0.10,-0.01)$ & 0.015 \\
\hline Body mass index $\left(\mathrm{kg} / \mathrm{m}^{2}\right)$ & $25.0 \pm 4.4(|2.6-4| .4)(n=386)$ & $-0.02(-0.08,0.04)$ & 0.53 \\
\hline
\end{tabular}

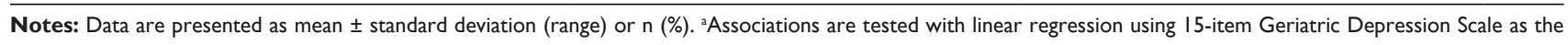
dependent variable.

Abbreviations: ASA, acetylsalicylic acid; Cl, confidence interval. 
dent variable was the GDS-15 score and independent variables were the BBS score, overall Barthel ADL Index score, and the dichotomized Barthel ADL tasks, respectively. Age, sex, and descriptive characteristics found to be associated with the GDS-15 score $(P \leq 0.15)$ in univariate analyses (Table 1$)$ were added to the multivariate linear regression models after all variables were controlled for multicollinearity $(r \geq 0.7)$. Given the high correlation $(r=-0.74)$ between dependency in the ADL task of bathing and living in a residential care facility, the latter was not controlled for when analyzing the former. In addition, four variables (depression, MMSE score, benzodiazepine use, and antidepressant use) were not included in any multivariate regression model. Depression diagnosis was not included since the dependent variable was the GDS-15 score, which measures depressive symptoms. MMSE scores correlated moderately with dementia $(r=0.63)$, but both variables were considered to be measures of cognitive function. As dementia diagnosis has been associated more consistently with depression in the literature and MMSE scores can be falsely low among depressed older people, MMSE scores were excluded from the analyses. Benzodiazepine and antidepressant use were considered to be effects rather than causes of depression and were not included in the analyses. Interaction effects between BBS score and Barthel ADL Index score, respectively, and sex, dementia, and living in a residential care facility were also evaluated in multivariate linear regression analyses. The rationale for evaluating the interaction effect of dementia was that cognitive impairment, in addition to physical impairment, contributes to dependency on assistance in ADL and might thus affect the association between BBS or Barthel ADL Index and GDS-15, respectively. The interaction effect of living in a residential care facility was evaluated with the rationale that an increased access to care staff might influence the amount of assistance received, irrespective of level of physical impairment, compared to when community dwelling. Furthermore, the interaction analysis of living in a residential care facility was performed to investigate whether differences in living arrangements between the datasets influenced the associations; all the participants in FOPANU/REMANU lived in residential care facilities, but only a portion of the participants in Umeå 85+/GERDA resided in facilities. IBM SPSS Statistics version 20.0 (IBM Corp, Armonk, NY, USA) was used for statistical analyses. All statistical tests were two tailed and $P<0.05$ was considered to indicate statistical significance.

\section{Results}

This study included data from 392 participants (Figure 1); their characteristics are shown in Table 1. The mean age was 86.2 years (range, 65-103), 282 (72\%) participants were women, and $264(67 \%)$ were living in residential care facilities. One hundred sixty-six (42\%) participants were diagnosed with depression, and 132 (34\%) were using antidepressants. The mean \pm standard deviations (SD) MMSE score was 20.5 26.0 (range, 8-30), and 153 (39\%) participants were diagnosed with dementia.

The mean \pm SD GDS-15 score was 3.9 \pm 2.8 (range, 0-14). No significant difference was found between mean \pm SD GDS-15 scores of men and women (3.8 \pm 2.9 versus $4.0 \pm 2.7$, $P=0.39)$. The mean \pm SD GDS-15 score of the participants with and without depression was 5.3 \pm 3.2 and 3.0 \pm 1.9 , respectively $(P<0.001)$. Of the 166 participants with depression, $129(78 \%)$ were using antidepressants, and $77(60 \%)$ of them had responded to treatment (GDS-15<5). The nonresponders had a mean \pm SD GDS-15 score of 7.9 \pm 2.4 . Two hundred ninety-three (75\%) participants were dependent in ADLs (Barthel Index <20), and mean scores \pm SD (ranges) for the Barthel ADL Index and BBS were 15.4 $\pm 4.8(0-20)$ and 33.3 $\pm 16.8(0-56)$, respectively.

Among the individual ADL tasks of Barthel ADL Index, the highest rate of dependency was found in bathing (70\%) and the lowest in bowel continence (13\%) (Table 2). There was a significant difference in GDS-15 scores between independency and dependency in all ADL tasks except in bowel continence, bladder continence, and bathing (Table 2).

In univariate linear regression analyses, BBS score, Barthel ADL Index score, and dependency in all ADL tasks except bowel continence, bladder continence, and bath-

Table 2 GDS-15 scores of participants independent and dependent in individual tasks of Barthel ADL Index $(n=392)$

\begin{tabular}{|c|c|c|c|c|}
\hline \multirow{2}{*}{$\begin{array}{l}\text { Tasks of } \\
\text { Barthel } \\
\text { ADL Index }\end{array}$} & \multirow{2}{*}{$\begin{array}{l}\text { Participants } \\
\text { dependent, } \\
\text { n (\%) }\end{array}$} & \multicolumn{2}{|c|}{ GDS-I5, mean \pm SD } & \multirow[t]{2}{*}{$P$} \\
\hline & & Independent & Dependent & \\
\hline $\begin{array}{l}\text { Bowel } \\
\text { continence }\end{array}$ & $52(13)$ & $3.91 \pm 2.63$ & $4.19 \pm 3.63$ & 0.59 \\
\hline $\begin{array}{l}\text { Bladder } \\
\text { continence }\end{array}$ & $\mid 22(3 \mid)$ & $3.79 \pm 2.6 \mathrm{I}$ & $4.29 \pm 3.10$ & 0.13 \\
\hline Grooming & $99(25)$ & $3.75 \pm 2.58$ & $4.54 \pm 3.24$ & 0.03 \\
\hline Toilet use & $88(22)$ & $3.7 I \pm 2.52$ & $4.75 \pm 3.42$ & 0.009 \\
\hline Feeding & $58(15)$ & $3.80 \pm 2.73$ & $4.78 \pm 2.92$ & 0.01 \\
\hline Transfer & $73(19)$ & $3.62 \pm 2.49$ & $5.36 \pm 3.47$ & $<0.001$ \\
\hline Mobility & $90(23)$ & $3.69 \pm 2.53$ & $4.8 \mathrm{I} \pm 3.37$ & 0.004 \\
\hline Dressing & $166(42)$ & $3.54 \pm 2.43$ & $4.50 \pm 3.12$ & 0.001 \\
\hline Stairs & $246(63)$ & $3.44 \pm 2.27$ & $4.25 \pm 3.00$ & 0.003 \\
\hline Bathing & $274(70)$ & $3.64 \pm 2.36$ & $4.08 \pm 2.94$ & 0.12 \\
\hline
\end{tabular}

Notes: Between-group differences were analyzed using independent samples $t$-test. For GDS-15, higher scores indicate more depressive symptoms.

Abbreviations: ADL, activities of daily living; GDS- I5, I5-item Geriatric Depression Scale; SD, standard deviation. 
Table 3 Univariate and multivariate linear regression analyses for associations between GDS-I5 and Berg Balance Scale, GDS-I5 and Barthel ADL Index, and GDS-I5 and each individual ADL task of Barthel ADL Index, separately ${ }^{\mathrm{a}}$

\begin{tabular}{|c|c|c|c|c|c|}
\hline \multirow[t]{2}{*}{ Characteristic } & \multicolumn{2}{|c|}{$\begin{array}{l}\text { Univariate linear regression analyses } \\
n=392\end{array}$} & \multicolumn{2}{|c|}{$\begin{array}{l}\text { Multivariate linear regression analyses } \\
n=391\end{array}$} & \multirow[t]{2}{*}{$R^{2}$} \\
\hline & Unstandardized b $(95 \% \mathrm{Cl})$ & $\mathbf{P}$ & Unstandardized b $(95 \% \mathrm{Cl})$ & $P$ & \\
\hline Berg Balance Scale & $-0.04(-0.06,-0.03)$ & $<0.001$ & $-0.03(-0.05,-0.01)$ & 0.008 & 0.174 \\
\hline Barthel ADL Index & $-0.12(-0.18,-0.06)$ & $<0.001$ & $-0.07(-0.14,0.004)$ & 0.068 & 0.166 \\
\hline \multicolumn{6}{|c|}{ Dependency in individual tasks of Barthel ADL Index } \\
\hline Bowel continence & $-0.39(-0.88,0.11)$ & 0.12 & $-0.02(-0.83,0.79)$ & 0.96 & 0.158 \\
\hline Bladder continence & $-0.27(-0.62,0.08)$ & 0.13 & $0.09(-0.54,0.7 \mathrm{I})$ & 0.79 & 0.158 \\
\hline Grooming & $-0.79(-1.42,-0.16)$ & 0.015 & $-0.4 I(-1.06,0.25)$ & 0.22 & 0.161 \\
\hline Toilet use & $-0.66(-1.05,-0.28)$ & $<0.001$ & $-0.47(-1.17,0.24)$ & 0.19 & 0.162 \\
\hline Feeding & $-1.01(-1.69,-0.33)$ & 0.004 & $-0.36(-1.14,0.42)$ & 0.36 & 0.160 \\
\hline Transfer & $-0.95(-1.36,-0.54)$ & $<0.001$ & $-1.03(-1.77,-0.29)$ & 0.007 & 0.175 \\
\hline Mobility & $-0.55(-0.87,-0.23)$ & $<0.001$ & $-0.57(-1.26,0.13)$ & 0.11 & 0.164 \\
\hline Dressing & $-0.79(-1.15,-0.44)$ & $<0.001$ & $-0.70(-1.35,-0.05)$ & 0.035 & 0.168 \\
\hline Stairs & $-0.50(-0.79,-0.20)$ & $<0.001$ & $0.05(-0.76,0.86)$ & 0.90 & 0.158 \\
\hline Bathing & $-0.43(-1.03,0.17)$ & 0.16 & $0.03(-0.67,0.74)$ & 0.93 & 0.156 \\
\hline
\end{tabular}

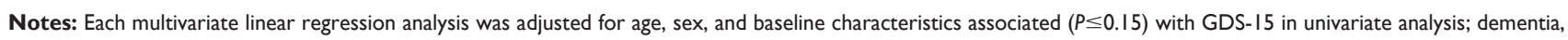
previous stroke, current urinary tract infection, angina pectoris, malignancy in the last 5 years, constipation, rheumatic disease, diuretics, analgesics, acetylcholinesterase inhibitors, number of drugs used regularly, and visual impairment. Living in residential care facility was adjusted for in all multivariate analyses except for that of the ADL item bathing. ${ }^{a}$ GDS-I 5 was used as dependent variable.

Abbreviations: ADL, activities of daily living; Cl, confidence interval; GDS-15, I5-item Geriatric Depression Scale.

ing were significantly and inversely associated with the GDS-15 score (Table 3). In the multivariate linear regression analyses, the BBS score was found to be significantly and inversely associated with the GDS-15 score (unstandardized $b=-0.03, P=0.008)$, but the Barthel ADL Index score was not (unstandardized $b=-0.07, P=0.068$ ). No significant interaction effect was found between the BBS score and Barthel ADL Index score, respectively, and sex $(P=0.48$ and $P=0.91$, respectively), dementia ( $P=0.99$ and $P=0.72$, respectively), or living in a residential care facility $(P=0.33$ and $P=0.20$, respectively). Multivariate regression analyses examining associations between GDS-15 score and dependency in each individual ADL task, separately, revealed that dependency in transfer and dressing were significantly and inversely associated with the GDS-15 score (unstandardized $b=-1.03$, $P=0.007$ and unstandardized $b=-0.70, P=0.035$, respectively) (Table 3). In additional analyses, comparing differences in BBS scores between participants independent or dependent in the ADL tasks of transfer and dressing, the mean \pm SD scores were $38.7 \pm 12.8$ versus $9.71 \pm 10.6(P<0.001)$ and $41.9 \pm 11.4$ versus $21.7 \pm 16.0(P<0.001)$, respectively.

\section{Discussion}

This study comprised a heterogeneous sample with a high mean age, a large range of functional capacity, a wide spectrum of dependency in ADLs, and a high prevalence of comorbidities. In this sample, reduced functional capacity and dependency in transfer and dressing were independently associated with the presence of more depressive symptoms, after comprehensive adjustment. However, overall dependency in ADLs was not independently associated with depressive symptoms. According to interaction analyses, sex, dementia, or living in a residential care facility did not influence the associations between depressive symptoms and functional capacity or between depressive symptoms and overall dependency in ADLs.

In contrast to the present study, the majority of previous observational studies performed among very old people have shown that overall ADL dependency was independently associated with depressive symptoms. ${ }^{11,12,14,15}$ This difference in results may be related to less extensive adjustment for potential confounders in previous studies, which was insufficient to appropriately characterize this association. In the present study, functional capacity, rather than ADL dependency, was associated with depressive symptoms. This finding is in accord with the results of an observational study conducted among very old community-dwelling people, in which comprehensive adjustment was performed. ${ }^{13}$ The observational study showed that low performance in tests of balance, lowerlimb strength, and gait speed was independently associated with depression, whereas overall dependency in ADLs was not. ${ }^{13}$ Together with the results of the present study, this may indicate that overall dependency in ADLs is not related to depressive symptoms, whereas lower functional capacity resulting in a higher rate of dependency is associated. The present study did not measure mediators of this association, 
such as physical activity, self-esteem, and self-efficacy, which may explain the results. For example, functional capacity might have a greater impact than ADL independence on the level of physical activity. Similarly, a person's physical ability to perform a task, rather than whether he or she receives help while doing it, may be more important for self-esteem or self-efficacy. Thus, knowing that you are able to perform a task might be more important than accepting to be helped in relation to depression.

Previous studies of ADL dependency have not investigated the impacts of individual ADL tasks on depression. One possible explanation for the associations of transfer and dressing with depressive symptoms in the present study may be that dependency in these ADL tasks particularly lowers self-esteem, self-efficacy, sense of control, and physical activity, which are suggested mediators between depressive symptoms and disability. ${ }^{17,19-22}$ People who are dependent in transfer need help with numerous activities throughout the day. Similarly, people who become dependent in dressing shift from almost complete independence in personal ADLs to requiring help several times a day: in the morning, in the evening, and when they want to go outside.

Overall, higher functional capacity, which depends on balance and lower-limb strength, appears to be associated with the presence of fewer depressive symptoms in older populations with a high prevalence of disability. Balance and lower-limb strength are important prerequisites for transfer and dressing. Not being able to independently dress or transfer (eg, from bed to chair) seems to be an important threshold prompting more depressive symptoms. In the present study the differences in mean of BBS score between those independent and dependent in transfer and dressing were 29.0 and 20.3 points, respectively. The small unstandardized $b$ values of the BBS in Table 3 indicate that a change in BBS score of this quantity also seems to be required to change the GDS-15 score approximately one point. Thus, to reduce depressive symptoms, a large improvement in functional capacity seems to be necessary. The unstandardized $b$ values of dressing and transfer indicate that a change from independent to dependent, or vice versa, in one of these activities might change the GDS-score with around one point. This could explain the inability of exercise interventions to reduce depressive symptoms in residential care facilities. ${ }^{38-41}$ Such interventions may have had insufficient effects on functional capacity, or an insufficient number of participants have managed to become independent in dressing or transfer. In future studies it may be of interest to evaluate the effects on depressive symptoms of interdisciplinary multifactorial rehabilitation programs, by combining physical exercise, specific skill training, and the assessment and fitting of appropriate assistive devices, targeting dependency in transfer and dressing.

Some potential limitations of the present study should be considered. The cross-sectional design limits interpretation of the directions of observed associations. However, longitudinal studies among older people with a mean age below 80 years indicate both that depression is a risk factor for ADL dependency and that ADL dependency is a risk factor for depression. ${ }^{16-18}$ Many factors can contribute to depression in older people. Although we had access to information about many potential confounders compared with other studies, additional factors might have influenced the associations found. The study sample was heterogeneous, including subjects living in the community and in residential care facilities who represented the entire ranges of BBS scores, personal ADL dependency, and large variations in MMSE scores. As a result, this heterogeneous sample included many participants with severe cognitive and physical impairment: participants important to include in studies intending to thoroughly investigate the associations between depression and functional capacity or ADL dependency. By merging data from three studies, the study sample is neither representative of the very old population or of residential care facility populations, which may limit the external validity of the results. However, no significant interaction effect of sex, living conditions, or dementia was observed, indicating that our results may be applicable to both men and women, with and without dementia, living in the community as well as in residential care facilities.

\section{Conclusion}

Functional capacity seems to be independently associated with depressive symptoms in older people living in the community and in residential care facilities, whereas overall ADL performance may not be associated. Dependency in the individual ADL tasks of transfer and dressing appear to be independently associated with depressive symptoms and may be an important focus of future interdisciplinary multifactorial intervention studies.

\section{Acknowledgments}

This study was supported by funds from the European Union Bothnia-Atlantica Program, the King Gustav V and Queen Victoria's Foundation of Freemasons, the Umeå University Foundations for Medical Research, the Erik and Anne-Marie Detlof Research Foundation, the Swedish Dementia Association, the Alzheimer Foundation, Interreg IIIA 
Mitt-Scandia, the County Council of Västerbotten (ALF), and the Swedish Research Council (K2009-69P-21298-01-4, K2009-69X- 21299-01-1, K2009-69P-21298-04-4).

\section{Disclosure}

The authors report no conflicts of interest in this work.

\section{References}

1. Mathers CD, Fat DM, Boerma J. The Global Burden of Disease: 2004 Update. Geneva: World Health Organization; 2008.

2. Bergdahl E, Gustavsson JM, Kallin K, et al. Depression among the oldest old: the Umeå 85+ study. Int Psychogeriatr. 2005;17(4):557-575.

3. Weyerer S, Eifflaender-Gorfer S, Wiese B, et al. Incidence and predictors of depression in non-demented primary care attenders aged 75 years and older: results from a 3-year follow-up study. Age Ageing. 2013; 42(2):173-180.

4. Bergdahl E, Allard P, Gustafson Y. Depression among the very old with dementia. Int Psychogeriatr. 2011;23(5):756-763.

5. Enache D, Winblad B, Aarsland D. Depression in dementia: epidemiology, mechanisms, and treatment. Curr Opin Psychiatry. 2011;24(6):461-472.

6. Barry LC, Allore HG, Guo Z, Bruce ML, Gill TM. Higher burden of depression among older women: the effect of onset, persistence, and mortality over time. Arch Gen Psychiatry. 2008;65(2):172-178.

7. Wilkinson P, Izmeth Z. Continuation and maintenance treatments for depression in older people. Cochrane Database Syst Rev. 2012;11:CD006727.

8. Banerjee S, Hellier J, Dewey M, et al. Sertraline or mirtazapine for depression in dementia (HTA-SADD): a randomised, multicentre, double-blind, placebo-controlled trial. Lancet. 2011;378(9789):403-411.

9. Blazer D, Burchett B, Service C, George LK. The association of age and depression among the elderly: an epidemiologic exploration. J Gerontol. 1991;46(6):M210-M215.

10. Niccoli T, Partridge L. Ageing as a risk factor for disease. Curr Biol. 2012;22(17):R741-R752.

11. Forsell Y, Jorm AF, Winblad B. Association of age, sex, cognitive dysfunction, and disability with major depressive symptoms in an elderly sample. Am J Psychiatry. 1994;151(11):1600-1604.

12. Katz IR, Parmelee PA, Streim JE. Depression in older patients in residential care: significance of dysphoria and dimensional assessment. Am J Geriat Psychiat. 1995;3(2):161-169.

13. Russo A, Cesari M, Onder G, et al. Depression and physical function: results from the aging and longevity study in the Sirente geographic area (ilSIRENTE Study). J Geriatr Psychiatry Neurol. 2007;20(3):131-137.

14. Stek ML, Gussekloo J, Beekman AT, van Tilburg W, Westendorp RG. Prevalence, correlates and recognition of depression in the oldest old: the Leiden 85-plus study. J Affect Disord. 2004;78(3):193-200.

15. Yu LC, Johnson KL, Kaltreider DL, Craighead WE. The relationship between depression, functional status, and cognitive status among institutionalized elderly women. Behav Health Aging. 1993;3(1):23-32.

16. Bruce ML. Depression and disability in late life: directions for future research. Am J Geriatr Psychiatry. 2001;9(2):102-112.

17. Lenze EJ, Rogers JC, Martire LM, et al. The association of late-life depression and anxiety with physical disability: a review of the literature and prospectus for future research. Am J Geriatr Psychiatry. 2001;9(2): 113-135.

18. Schillerstrom JE, Royall DR, Palmer RF. Depression, disability and intermediate pathways: a review of longitudinal studies in elders. J Geriatr Psychiatry Neurol. 2008;21(3):183-197.

19. Åberg AC, Sidenvall B, Hepworth M, O'Reilly K, Lithell H. On loss of activity and independence, adaptation improves life satisfaction in old age - a qualitative study of patients' perceptions. Qual Life Res. 2005;14(4):1111-1125.

20. LeeY, Park K. Does physical activity moderate the association between depressive symptoms and disability in older adults? Int $J$ Geriatr Psychiatry. 2008;23(3):249-256.
21. Netz Y, Wu MJ, Becker BJ, Tenenbaum G. Physical activity and psychological well-being in advanced age: a meta-analysis of intervention studies. Psychol Aging. 2005;20(2):272-284.

22. Yang Y. How does functional disability affect depressive symptoms in late life? The role of perceived social support and psychological resources. J Health Soc Behav. 2006;47(4):355-372.

23. Verbrugge LM, Jette AM. The disablement process. Soc Sci Med. 1994;38(1):1-14.

24. von Heideken Wågert P, Gustavsson JM, Lundin-Olsson L, et al. Health status in the oldest old. Age and sex differences in the Umeå 85+ Study. Aging Clin Exp Res. 2006;18(2):116-126.

25. Rosendahl E, Lindelöf N, Littbrand H, et al. High-intensity functional exercise program and protein-enriched energy supplement for older persons dependent in activities of daily living: a randomised controlled trial. Aust J Physiother. 2006;52(2):105-113.

26. Conradsson M, Lundin-Olsson L, Lindelöf N, et al. Berg balance scale: intrarater test-retest reliability among older people dependent in activities of daily living and living in residential care facilities. Phys Ther. 2007;87(9):1155-1163.

27. Folstein MF, Folstein SE, McHugh PR. "Mini-mental state". A practical method for grading the cognitive state of patients for the clinician. J Psychiatr Res. 1975;12(3):189-198.

28. Sheikh J, Yesavage J. Geriatric Depression Scale (GDS): Recent evidence and development of a shorter version. Clinical Gerontology. 1986;5:165-173.

29. de Craen AJ, Heeren TJ, Gussekloo J. Accuracy of the 15-item geriatric depression scale (GDS-15) in a community sample of the oldest old. Int J Geriatr Psychiatry. 2003;18(1):63-66.

30. Smalbrugge M, Jongenelis L, Pot AM, Beekman AT, Eefsting JA. Screening for depression and assessing change in severity of depression. Is the Geriatric Depression Scale (30-, 15- and 8-item versions) useful for both purposes in nursing home patients? Aging Ment Health. 2008;12(2):244-248.

31. Conradsson M, Rosendahl E, Littbrand H, Gustafson Y, Olofsson B, Lövheim H. Usefulness of the Geriatric Depression Scale 15-item version among very old people with and without cognitive impairment. Aging Ment Health. 2013;17(5):638-645.

32. Berg K. Measuring balance in the elderly: preliminary development of an instrument. Physiother Can. 1989;41(6):304-311.

33. Berg KO, Wood-Dauphinee SL, Williams JI, Maki B. Measuring balance in the elderly: validation of an instrument. Can J Public Health. 1992;83(Suppl 2):S7-S11.

34. Collin C, Wade DT, Davies S, Horne V. The Barthel ADL Index: a reliability study. Int Disabil Stud. 1988;10(2):61-63.

35. Ranhoff AH. Reliability of nursing assistants' observations of functioning and clinical symptoms and signs. Aging (Milano). 1997; 9(5):378-380

36. Tombaugh TN, McIntyre NJ. The mini-mental state examination: a comprehensive review. J Am Geriatr Soc. 1992;40(9):922-935.

37. American Psychiatric Association. Diagnostic and Statistical Manual of Mental Disorders: DSM-IV-TR. Washington: American Psychiatric Publishing, Inc; 2000.

38. Chin A Paw MJ, van Poppel MN, Twisk JW, van Mechelen W. Effects of resistance and all-round, functional training on quality of life, vitality and depression of older adults living in long-term care facilities: a 'randomized' controlled trial [ISRCTN87177281]. BMC Geriatr. 2004;4:5.

39. Conradsson M, Littbrand H, Lindelöf N, Gustafson Y, Rosendahl E. Effects of a high-intensity functional exercise programme on depressive symptoms and psychological well-being among older people living in residential care facilities: A cluster-randomized controlled trial. Aging Ment Health. 2010;14(5):565-576.

40. Rolland Y, Pillard F, Klapouszczak A, et al. Exercise program for nursing home residents with Alzheimer's disease: a 1-year randomized, controlled trial. J Am Geriatr Soc. 2007;55(2):158-165.

41. Underwood M, Lamb SE, Eldridge S, et al. Exercise for depression in elderly residents of care homes: a cluster-randomised controlled trial. Lancet. 2013;382(9886):41-49. 
Clinical Interventions in Aging

\section{Publish your work in this journal}

Clinical Interventions in Aging is an international, peer-reviewed journal focusing on evidence-based reports on the value or lack thereof of treatments intended to prevent or delay the onset of maladaptive correlates of aging in human beings. This journal is indexed on PubMed Central, MedLine, the American Chemical Society's 'Chemical Abstracts Ser-

vice' (CAS), Scopus and the Elsevier Bibliographic databases. The manuscript management system is completely online and includes a very quick and fair peer-review system, which is all easy to use. Visit $\mathrm{http}: / /$ www.dovepress.com/testimonials.php to read real quotes from published authors.

Submit your manuscript here: http://www.dovepress.com/clinical-interventions-in-aging-journal 